\title{
DIAGNÓSTICO DAS BIBLIOTECAS ESCOLARES MUNICIPAIS DE VACARIA (RS): SITUAÇÃO ATUAL E PERSPECTIVAS
}

\author{
DIAGNOSIS OF MUNICIPAL SCHOOL LIBRARIES IN \\ VACARIA (RS): CURRENT SITUATION AND \\ PERSPECTIVES
}

\author{
Elisabete Costa da Silvaa \\ Tânia Regina da Rocha Unglaubb
}

\begin{abstract}
RESUMO
Introdução: Este artigo apresenta resultados parciais da pesquisa em andamento de Mestrado Profissional em Gestão de Unidades de Informação, da Universidade do Estado de Santa Catarina. Explora a temática da biblioteca escolar enquanto espaço educativo e de suporte pedagógico ao trabalho em parceria de professores com bibliotecários; trazendo o contexto das escolas públicas municipais de Vacaria, interior do estado do Rio Grande do Sul. Objetivo: Diagnosticar como se configuram essas bibliotecas escolares em relação aos seus espaços e serviços, bem como às práticas educativas voltadas para alunos dos anos iniciais do ensino fundamental. Metodologia: Trata-se de pesquisa de campo, tipo exploratória, com abordagem qualitativa, cujo corpus investigativo é constituído por 11 escolas públicas de Vacaria (RS). As quais são analisadas com base na Resolução n.ํ 220/2020 do Conselho Federal de Biblioteconomia, dos Parâmetros para bibliotecas escolares (CFB; GEBE, 2010) e das Diretrizes da IFLA para a biblioteca escolar (IFLA, 2016), e referenciais teóricos. Resultados: Apurou-se que as 11 escolas contam com espaço para a biblioteca, seis delas possuem acervo considerado exemplar (com quatro títulos por aluno). Há interesse por parte dos participantes em adquirir conhecimentos por meio de capacitação para melhor utilizar a biblioteca escolar. Contudo, verificou-se que as bibliotecas investigadas necessitam se adequar aos parâmetros normativos analisados. Conclusões: Foi possível conhecer o cenário educacional do município de Vacaria referente à biblioteca escolar - número de escolas com presença de bibliotecas, profissionais, recursos tecnológicos, estrutura, serviços, utilização da biblioteca e percepções da comunidade escolar sobre ela.
\end{abstract}

Descritores: Bibliotecas Escolares. Parâmetros para Biblioteca Escolar. Diagnóstico de

\footnotetext{
a Mestranda do Programa de Pós-Graduação Profissional em Gestão de Unidades de Informação da Universidade do Estado de Santa Catariana (UDESC). E-mail: betipimentinha2010@hotmail.com

b Doutora em História pela Universidade Federal de Santa Catarina (UFSC). Docente do Programa de Pós-Graduação em Gestão da Informação da Universidade do Estado de Santa Catariana (UDESC). E-mail: taniaunglaub@gmail.com
} 
Bibliotecas. Práticas Educativas.

\section{INTRODUÇÃO}

Este artigo configura-se em um recorte da dissertação que está sendo desenvolvida no Curso de Mestrado Profissional em Gestão de Unidades de Informação, do Programa de Pós-Graduação em Gestão da Informação (PPGInfo), da Universidade do Estado de Santa Catarina (UDESC). Com intuito de explorar a temática da biblioteca escolar enquanto espaço educativo e de suporte pedagógico ao trabalho em parceria de professores com bibliotecários, o estudo apresenta o contexto existente nas escolas públicas municipais da cidade de Vacaria, interior do estado do Rio Grande do Sul.

Referindo-se ao campo de pesquisa optou-se em explorar a rede municipal de ensino de Vacaria, pois esse contexto foi, primeiramente, um espaço representativo e com significado à memória da pesquisadora, tendo em vista que toda a sua caminhada escolar se realizou nessa cidade, assim como as suas relações profissionais. Nesse último caso, em especial, foram notadas carências no que se refere à interação de educadores com a biblioteca escolar por meio de percepções pessoais e empíricas no momento em que estava inserida nesse ambiente como profissional. Em segundo lugar, pela possibilidade de levantar dados relevantes sobre as bibliotecas escolares que possam contribuir (caso o órgão competente - Secretaria de Educação - tenha interesse) na melhoria das práticas e atividades desenvolvidas nesses espaços educativos pelos docentes dos anos iniciais ( $1^{\circ}$ ao $5^{\circ}$ ano) do ensino fundamental, os quais atendem alunos de 6 a 10 anos de idade.

Nessa perspectiva, buscou-se responder à seguinte problemática: Como se configuram as bibliotecas escolares da rede municipal de ensino de Vacaria em relação aos seus espaços e serviços, bem como às práticas educativas voltadas para turmas dos anos iniciais do ensino fundamental?

Há algum tempo a biblioteca escolar deixou de ser percebida como um anexo da escola e passou a conceber-se como "[...] centro dinamizador de leitura e difusor do conhecimento produzido pela coletividade, constituindo-se, dessa 
forma, na primeira oportunidade concreta de acesso ao patrimônio científico e cultural [...]" (MAROTO, 2009, p. 75) para os estudantes das escolas públicas.

Do mesmo modo, se observa que o papel da biblioteca escolar tem se refeito durante a construção de sua identidade como instituição educativa, incorporando-a, cada vez mais, nas questões pedagógicas e nos processos de ensino e aprendizagem dentro do contexto educacional. A recente Resolução $\mathrm{n}$. 220/2020, do Conselho Federal de Biblioteconomia (CFB), sustenta tal afirmação ao expor que a biblioteca escolar deve "[...] funcionar como espaço inovador e convidativo que propicie aprendizagem e criatividade" (CFB, 2020, p. 1). Portanto, partindo desses pressupostos é que se justifica a temática selecionada para o presente estudo.

Para a consecução desta pesquisa foram elaborados três instrumentos de coleta de dados, aplicados aos sujeitos participantes: um formulário utilizado durante visita às bibliotecas escolares, um questionário com perguntas de múltipla escolha aos professores dos anos iniciais do ensino fundamental e outro questionário similar respondido pelos bibliotecários e/ou profissionais atuantes ${ }^{1}$ nas bibliotecas investigadas.

Em consonância com a questão-problema estipulada, este artigo consiste, num primeiro momento, em um apanhado de referenciais teóricos que fundamentam a temática da biblioteca escolar no que tange ao seu conceito e objetivos, além de produtos, serviços e público, bem como as funções exercidas.

Em seguida, apresentam-se as diretrizes e padrões estipulados para as bibliotecas escolares, numa perspectiva do que é considerado o ideal para essa unidade de informação. Após, realiza-se a análise dos dados coletados na pesquisa exploratória destinada a refletir sobre o contexto investigado: as bibliotecas das 11 escolas municipais de ensino fundamental de Vacaria, verificando sua realidade comparada com os documentos supramencionados e as propostas de autores que versam sobre $o$ assunto.

Por fim, são elencadas algumas alternativas, além de exemplos de

\footnotetext{
1 No Brasil, mesmo havendo uma grande mobilização do Conselho Federal de Biblioteconomia, juntamente com amparos legais para a obrigatoriedade de bacharéis em Biblioteconomia atuarem em bibliotecas escolares, ainda há uma realidade com professores readaptados ou deslocados trabalhando nas bibliotecas.
} 
atividades e projetos já experimentados, que potencializam as perspectivas das unidades de informação pesquisadas, com a intenção de aportar ideias de melhorias e inovação das bibliotecas, pensando na integração desse espaço com a sala de aula, e do bibliotecário com o professor em prol do aprendizado dos educandos.

\section{A BIBLIOTECA ESCOLAR}

Serão abordadas as principais características atribuídas à biblioteca escolar: conceito e objetivos, produtos, serviços e público, além das funções exercidas. Apresentam-se, também, as diretrizes e padrões estipulados para as bibliotecas escolares - baseados em documento do Grupo de Estudos em Biblioteca Escolar (GEBE), e na legislação brasileira vigente.

\subsection{BIBLIOTECA ESCOLAR: CONCEITOS E OBJETIVOS}

Norteando as concepções para este estudo, torna-se essencial debater acerca do espaço no qual os agentes mediadores do processo educativo professores e bibliotecários - trabalharão com os educandos: a biblioteca escolar.

A Lei $n .$. 12.244, no artigo 2.. (BRASIL, 2010, p. 3) e a Resolução n.ㅇ 220/2020, artigo 1.ㅇ (CFB, 2020, p. 1) consideram que biblioteca escolar é " $[\ldots .$.$] a$ coleção de livros, materiais videográficos e documentos registrados em qualquer suporte destinados à consulta, pesquisa, estudo ou leitura". Percebendo a definição um tanto simplória e pouco representativa do real papel desta instituição educativa, foi aprovado, pela Comissão de Educação da Câmara de Deputados Federais, o Projeto de Lei n. $.9 .484 / 18$ (e, atualmente, em tramitação no Senado Federal sob o n. 5.656/19), apresentando um novo conceito de biblioteca escolar:

Art. 2. Para os fins desta Lei considera-se biblioteca escolar o equipamento cultural obrigatório e necessário ao desenvolvimento do processo educativo, cujos objetivos são:

I - disponibilizar e democratizar a informação, ao conhecimento e às novas tecnologias, em seus diversos suportes;

II - promover as habilidades, competências e atitudes que 
contribuam para a garantia dos direitos e objetivos de aprendizagem e desenvolvimento do(a)s aluno(a)s, em especial no campo da leitura e da escrita;

III - constituir-se como espaço de recursos educativos, indissociavelmente integrado ao processo de ensinoaprendizagem;

IV - apresentar-se como espaço de estudo, encontro e lazer, destinado a servir de suporte para a comunidade em suas necessidades e anseios (BRASIL, 2018, p. 2).

Outros dois documentos vêm ao encontro dessas considerações: 0 Manifesto da Biblioteca Escolar, afirmando que "[...] a biblioteca escolar é parte integrante do processo educativo" (IFLA/UNESCO, 2000, p. 2). E as Diretrizes para a Biblioteca Escolar, considerando que

a biblioteca escolar é um espaço de aprendizagem físico e digital na escola, onde a leitura, pesquisa, investigação, pensamento, imaginação e criatividade são fundamentais para o percurso dos alunos da informação ao conhecimento e para seu crescimento pessoal, social e cultural" (IFLA/UNESCO, 2016, p. 19).

Ainda tendo como referência a Federação Internacional de Associações

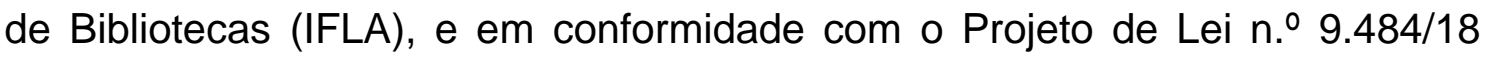
(BRASIL, 2018), definem-se como principais objetivos da biblioteca escolar "[...] desenvolver alunos letrados em informação que participem responsável e eticamente na sociedade" (IFLA, 2016, p. 9) e "[...] o reforço do "ensino e aprendizagem para todos" (IFLA, 2016, p. 15).

Portanto, por meio desses aspectos legais e normativos, os quais reconhecem a biblioteca escolar como um espaço ativo de aprendizagem, percebe-se, segundo Campello (2003, p. 29), “[...] a necessidade de ser este o momento de se ampliar a função pedagógica da biblioteca (ou, em outras palavras, construir um novo paradigma educacional para a biblioteca)".

Dessa forma, a biblioteca escolar deve transpor o que anteriormente se acreditava: que ela era um lugar de armazenamento, preservação e organização do acervo, além de sua limitação de serviços reduzida ao empréstimo de livros. Atualmente, mais importante do que essas atribuições, a biblioteca escolar deve configurar-se em um ambiente de aprendizagem das pessoas.

Nesta concepção, a biblioteca escolar atua como suporte informacional, estando integrada ao projeto pedagógico e curricular da escola, configurando-se em um espaço educativo e promotor de cultura. Sendo hoje a biblioteca um 
centro de recursos de aprendizagem, ela desempenha um papel primordial dentro do contexto educacional.

\subsection{BIBLIOTECA ESCOLAR: PRODUTOS, SERVIÇOS E PÚBLICO}

A biblioteca escolar precisa estar organizada para ser um instrumento de apoio educacional, trazendo contribuições para os processos de ensino e aprendizagem. Para tanto, é essencial estarem bem definidos os produtos e serviços que serão disponibilizados ao público.

Fins dos anos 90, Hillesheim e Fachin (1999) perceberam a importância da seleção do acervo da biblioteca e sua disponibilização a professores e estudantes, bem como a organização do espaço para aproximar esses usuários da leitura e do livro e enriquecer a dinâmica do processo de ensinar e aprender. Mas, para que tal ação aconteça efetivamente, o bibliotecário deve conhecer seu público. Assim, terá maior facilidade de desenvolver serviços e programas que motivem os usuários a frequentarem a biblioteca. Conhecendo seu público, é possível compor acervo e serviços de qualidade que realmente atendam as expectativas da comunidade escolar.

É importante destacar que os serviços e produtos disponibilizados devem estar alinhados com os objetivos da biblioteca e da própria escola a que pertence. Para tanto, as Diretrizes da IFLA para a biblioteca escolar trazem na recomendação 14 o seguinte:

Os serviços e programas fornecidos através da biblioteca escolar devem ser desenvolvidos de forma colaborativa por um bibliotecário escolar profissional, trabalhando em conjunto com o diretor, os responsáveis por departamentos curriculares, colegas de ensino, responsáveis de outras bibliotecas e membros da comunidade com características culturais, linguísticas ou étnicas específicas, de forma a contribuir para a consecução dos objetivos acadêmicos, culturais e sociais da escola. (IFLA, 2016, p. 13)

O mesmo documento propõe que os serviços da biblioteca escolar incluam:

a) Formação profissional para o corpo docente (por exemplo, sobre leitura e literacia, tecnologia, processos de investigação e pesquisa);

b) Um programa estimulante de literatura/ leitura tendo em vista 
o sucesso educativo, o prazer e enriquecimento pessoal;

c) Aprendizagem baseada em investigação e desenvolvimento da literacia da informação; e

d) Colaboração com outras bibliotecas (públicas, governamentais, de recursos comunitários). (IFLA, 2016, p. 23)

Logo, torna-se notável que um ponto importante, no que tange à biblioteca escolar e que será o alicerce de seu sucesso, é a oferta de produtos e serviços. Só existirá público frequentador se a unidade de informação disponibilizar serviços e produtos que interessem ao usuário, do contrário, será apenas um espaço de guarda de acervo bibliográfico.

\subsection{BIBLIOTECA ESCOLAR: FUNÇÃO}

Retoma-se que a biblioteca escolar é um espaço social que potencializa o trabalho individual ou em grupo, a troca de informação, ideias e conhecimento. Nela também se realiza o processo de educação continuada, como visto anteriormente.

Isso ocorre porque o papel da biblioteca escolar também se reformulou no decorrer dos anos. Lourense H. Das (2008) explica que, na era pré-digital, a biblioteca centrava seu papel no desenvolvimento da competência em leitura. Atualmente, ela se preocupa também com outras competências, como por exemplo, a competência em informação. Tal premissa parte da constatação de que os novos princípios e os modelos de aprendizagem trabalham com conceitos construtivistas de aquisição de conhecimento de forma autônoma e individual, pois é reconhecido que os alunos têm diferentes estilos de aprendizagem, ou seja, cada um aprende de um jeito e no seu ritmo.

Em síntese, as mudanças educacionais atingiram também o aluno na forma de aprender e no lugar onde aprende. Essas mudanças na aprendizagem, em especial, a individualização do ato de aprender, permitem que o processo educacional aconteça em outros formatos que não só o da sala de aula (DAS, 2008). E é dentro desse contexto que a biblioteca escolar se insere com a função de facilitadora dessa nova forma de aprendizagem. Corroborando sobre a função e importância da biblioteca no ambiente escolar, Bedin, Chagas e Sena (2015, p. 365) afirmam que é nela que se disponibiliza 
[...] a informação capaz de promover o processo de aprendizagem nas crianças, não só para as pesquisas escolares, mas para a vida toda. É essencial destacar que a infância é o período apropriado para inserir as crianças na formação de cidadãos competentes no uso da informação e a biblioteca é o cenário ideal para iniciar estas atividades buscando a competência informacional.

Embora a biblioteca escolar seja esse espaço importante dentro da escola, ela somente será efetivamente um lugar de aprendizagem se docentes e educandos conhecerem e utilizarem as ferramentas necessárias na busca e uso da informação nela contida, e usufruírem desse espaço na sua totalidade de possibilidades. Só assim, a função educativa da biblioteca será legitimada.

\subsection{BIBLIOTECA ESCOLAR: DIRETRIZES E PADRÕES}

Outros aspectos pertinentes a serem explorados referem-se aos parâmetros, ou ainda, os critérios que definem se determinada estrutura configura-se como biblioteca escolar. Diz-se isso, tendo em vista que no cenário educacional brasileiro existem as salas de leitura, enquanto espaços educativos, nas instituições de Educação Básica.

Todavia, retomando a menção aos parâmetros e critérios recomendados para avaliação das bibliotecas escolares no contexto brasileiro, numa perspectiva de quais são as expectativas para essa unidade de informação, têmse: a Resolução n. 220/2020 (CFB, 2020) e os Parâmetros para Bibliotecas Escolares (CFB, 2010).

Além desses dois documentos norteadores, no estado do Rio Grande do Sul - onde estão as escolas pesquisadas - a Secretaria de Educação (SEDUC) possui um setor destinado ao Sistema Estadual de Bibliotecas Escolares (SEBE), que atua nas 30 Coordenadorias Regionais de Ensino, englobando todas as escolas estaduais e municipais do RS. Essa estrutura administrativa visa "[...] integrar, coordenar e fomentar o desenvolvimento dos serviços bibliotecários nas escolas do Estado, bem como os projetos e realizações de incentivo à leitura" (RIO GRANDE DO SUL, 2019?).

Em consonância com suas atribuições, o SEBE elaborou um Manual de Procedimentos voltado à dinamização das bibliotecas escolares do RS - com 
última atualização de edição no ano de 2014. As diretrizes apontadas no material disponibilizado na página online da SEDUC consideram como propósito da biblioteca escolar:

[...] aliar as políticas e os programas educacionais, estabelecidos pela Secretaria de Estado da Educação do Rio Grande do Sul (SEDUC), às propostas do Projeto Político-Pedagógico da Escola e às finalidades e políticas biblioteconômicas, sintetizadas no Manifesto IFLA/UNESCO (RIO GRANDE DO SUL, 2014, p. 10).

Isto posto, apresenta-se a seguir uma síntese dos critérios e parâmetros que compõem os documentos mencionados. Salienta-se que para este estudo optou-se por trazer apenas aqueles padrões recomendados como exemplares e, portanto, compreendidos como o ideal proposto para as bibliotecas escolares².

Tabela 1 - Parâmetros para bibliotecas escolares: espaço físico

\begin{tabular}{l|l|l}
\hline \multicolumn{2}{c}{ ESPAÇO FísICO } & \multicolumn{1}{c}{ Resolução 220/2020 CFB } \\
\hline $\begin{array}{l}\text { Acessível a todos } \\
\text { os usuários: }\end{array}$ & Exemplar: acima de $300 \mathrm{~m}^{2}$. & \\
\hline $\begin{array}{l}\text { Assentos para } \\
\text { acomodar } \\
\text { usuários: }\end{array}$ & $\begin{array}{l}\text { Exemplar: assentos suficientes } \\
\text { para acomodar simultaneamente } \\
\text { uma classe inteira, usuários avulsos } \\
\text { e grupos de alunos. }\end{array}$ & $\begin{array}{l}\text { Área mínima de } 50 \mathrm{~m}^{2} \mathrm{com} \\
\text { mobiliário e equipamentos } \\
\text { adequados ao atendimento } \\
\text { satisfatório da comunidade } \\
\text { escolar. }\end{array}$ \\
\hline $\begin{array}{l}\text { Ambiente para } \\
\text { serviços técnicos } \\
\text { e administrativos: }\end{array}$ & $\begin{array}{l}\text { Exemplar: um balcão de } \\
\text { atendimento e ambiente específico } \\
\text { para atividades técnicas, com uma } \\
\text { mesa, uma cadeira e um } \\
\text { computador com acesso à internet, } \\
\text { para uso exclusivo de cada um dos } \\
\text { funcionários. }\end{array}$ & \\
\hline
\end{tabular}

Fonte: elaborada pela autora (2020), com base em CFB (2020), CFB e GEBE (2010).

Tabela 2 - Parâmetros para Bibliotecas Escolares: Acervo

\begin{tabular}{l|l|l}
\hline \multicolumn{2}{c}{ ACERVO } \\
\hline \multicolumn{2}{c}{ Parâmetros CFB/GEBE } & \multicolumn{1}{c}{ Resolução 220/2020 CFB } \\
\hline $\begin{array}{l}\text { Biblioteca conta com } \\
\text { acervo de livros } \\
\text { compatível com o no }\end{array}$ & $\begin{array}{l}\text { Exemplar: a partir de quatro } \\
\text { tétulos por aluno, não sendo }\end{array}$ & $\begin{array}{l}\text { Exigência de, no mínimo, } \\
\text { um título por aluno } \\
\text { necessário mais do que cinco } \\
\text { matriculado, contemplando a } \\
\text { diversidade de gêneros e } \\
\text { estilos literários, com }\end{array}$ \\
\hline
\end{tabular}

2 Para ter acesso à integra dos documentos e aos parâmetros e critérios completos com apresentação dos níveis: irregular, básico e exemplar, acessar: http://www.cfb.org.br/wpcontent/uploads/2016/05/2-MIOLO.pdf. http://repositorio.cfb.org.br/handle/123456789/1349 


\begin{tabular}{l|l|l}
\hline & & $\begin{array}{l}\text { autores nacionais e } \\
\text { estrangeiros. }\end{array}$ \\
\hline $\begin{array}{l}\text { Computadores } \\
\text { ligados à internet } \\
\text { são usados na } \\
\text { biblioteca como } \\
\text { fonte de informação, } \\
\text { complementando o }\end{array}$ & $\begin{array}{l}\text { Exemplar: computadores } \\
\text { ligados à internet para uso } \\
\text { exclusivo de professores e } \\
\text { ensino/aprendizagem, em } \\
\text { número suficiente para uma } \\
\text { classe inteira. }\end{array}$ & $\begin{array}{l}\text { A biblioteca deve promover } \\
\text { o acesso a informações } \\
\text { digitais. }\end{array}$ \\
\hline $\begin{array}{l}\text { O acervo é } \\
\text { organizado para } \\
\text { permitir que os } \\
\text { materiais sejam } \\
\text { encontrados com } \\
\text { facilidade e rapidez: }\end{array}$ & $\begin{array}{l}\text { Exemplar: o catálogo da } \\
\text { biblioteca é informatizado e } \\
\text { possibilita o acesso remoto a } \\
\text { todos os itens do acervo; permite } \\
- \text { além de recuperação por autor, } \\
\text { título e assunto - recuperação } \\
\text { por outros pontos de acesso. }\end{array}$ & $\begin{array}{l}\text { O acervo deve atender ao } \\
\text { quesito de catalogação } \\
\text { adequada. }\end{array}$ \\
\hline
\end{tabular}

Fonte: elaborada pela autora (2020), com base em CFB (2020), CFB e GEBE (2010).

Tabela 3 - Parâmetros para bibliotecas escolares: serviços e atividades

\section{SERVIÇOS E ATIVIDADES}

\begin{tabular}{l|l|l}
\hline \multicolumn{2}{c|}{ Parâmetros CFB/GEBE } & Resolução 220/2020 CFB \\
\hline & $\begin{array}{l}\text { Exemplar: consulta local, empréstimo } \\
\text { domiciliar, atividade de incentivo à }\end{array}$ & $\begin{array}{l}\text { Possibilitar consulta no } \\
\text { local, empréstimo }\end{array}$ \\
$\begin{array}{l}\text { A biblioteca } \\
\text { oferece serviços } \\
\text { regularmente: }\end{array}$ & $\begin{array}{l}\text { leitura e orientação à pesquisa, serviço } \\
\text { de divulgação de novas aquisições, } \\
\text { exposições e serviços para os } \\
\text { professores (levantamento } \\
\text { bibliográfico e boletim de alerta). }\end{array}$ & $\begin{array}{l}\text { incentivo à leitura e } \\
\text { orientação à pesquisa } \\
\text { escolar. }\end{array}$ \\
\hline
\end{tabular}

Fonte: Elaborada pela autora (2020), com base em CFB (2020), CFB e GEBE (2010).

Tabela 4 - Parâmetros para bibliotecas escolares: pessoal e divulgação

PESSOAL E DIVULGAÇÃO

\section{Parâmetros CFB/GEBE}

\begin{tabular}{|c|c|c|}
\hline $\begin{array}{l}\text { A biblioteca conta com } \\
\text { bibliotecário responsável } \\
\text { e funcionários para } \\
\text { atendimento aos } \\
\text { usuários em todos os } \\
\text { turnos em que a escola } \\
\text { está aberta: }\end{array}$ & $\begin{array}{l}\text { Exemplar: um bibliotecário } \\
\text { responsável pela biblioteca e } \\
\text { pessoal auxiliar em cada } \\
\text { turno, de acordo com o } \\
\text { número de alunos da escola. }\end{array}$ & $\begin{array}{l}\text { A biblioteca deve ser } \\
\text { administrada por bacharéis } \\
\text { em Biblioteconomia } \\
\text { registrados em seu órgão } \\
\text { de classe, auxiliados por } \\
\text { equipes em quantidade e } \\
\text { qualidade adequadas. }\end{array}$ \\
\hline - & - & $\begin{array}{l}\text { Divulgar orientações de } \\
\text { guarda, preservação, } \\
\text { organização e } \\
\text { funcionamento das } \\
\text { bibliotecas escolares. }\end{array}$ \\
\hline
\end{tabular}

Fonte: Elaborada pela autora (2020), com base em CFB (2020), CFB e GEBE (2010). 
As Tabelas 1, 2, 3 e 4 apresentam: de um lado, os parâmetros sugeridos como mais adequados (nível exemplar) às características da biblioteca escolar, estruturados pelo GEBE, na Universidade Federal de Minas Gerais (UFMG); de outro, trazem o que é proposto na Resolução $n . .220 / 2020$ do CFB. Tais parâmetros foram os norteadores da aplicação do formulário de visita às bibliotecas escolares pesquisadas.

$\mathrm{Na} 25^{\mathrm{a}}$ edição da Bienal Internacional do Livro, em 2018, o Conselho Regional de Biblioteconomia de São Paulo (CRB-8) apresentou uma 'Biblioteca Modelo' estruturada a partir dos parâmetros estipulados para bibliotecas escolares ${ }^{3}$.

\section{DIAGNÓSTICO DAS BIBLIOTECAS ESCOLARES MUNICIPAIS DE VACARIA}

Para a elaboração deste diagnóstico foram analisadas as bibliotecas das 11 escolas da rede municipal de ensino de Vacaria/RS e seus educadores: docentes dos anos iniciais do ensino fundamental e os bibliotecários e/ou profissionais que estariam desempenhando alguma função nas bibliotecas escolares.

Realizou-se pesquisa de campo de cunho exploratório, com pressupostos metodológicos da abordagem qualitativa. Foram utilizados três instrumentos de coleta de dados: um formulário para cada biblioteca escolar, um questionário com perguntas de múltipla escolha para os professores dos anos iniciais e outro similar respondido pelos bibliotecários e/ou profissionais atuantes. A partir da coleta e análise dos dados, apresentam-se os resultados parciais da pesquisa em desenvolvimento.

Contextualizando o espaço: Vacaria é uma cidade brasileira localizada na região nordeste do estado do Rio Grande do Sul, com área de 2.124 .582 km²; sua população é 65.846 habitantes segundo dados do Instituto Brasileiro de Geografia e Estatística (IBGE).

\footnotetext{
${ }^{3}$ Maiores informações e imagens sobre a 'Biblioteca Modelo' se encontram na página do CRB8. http://www.crb8.org.br/biblioteca-escolar-modelo-na-bienal-internacional-do-livro-2018/
} 
Em relação às escolas investigadas, constatou-se que todas possuem biblioteca, e uma delas conta também com sala de leitura. Para o item de Pessoal, apenas uma possui bibliotecário (nível exemplar), nove contam com professores realizando o atendimento, e uma escola não há responsável pelo espaço. Quanto ao quesito capacitação para atuar em biblioteca escolar, todos afirmaram nunca ter participado de algum curso na área. Outro aspecto observado é que nas nove escolas em que professores atuam nas bibliotecas, esses profissionais dividem-se em dois grupos: docentes aposentados que continuam trabalhando (três), e professores afastados da docência por motivo de saúde (seis).

Quanto ao espaço físico, no item assentos para acomodar usuários, uma única biblioteca se encaixa como exemplar. Aspectos como horário de funcionamento, área física, mobiliário e equipamentos, disponibilidade de ebooks, acesso a computadores e internet enquadraram todas as bibliotecas entre os níveis básico e irregular.

Importa notar que duas escolas têm sala de vídeo integrada à biblioteca, mas alguns professores indicaram que as atividades de leitura e pesquisa são prejudicadas durante a exibição de filmes ou reuniões naquele espaço.

Em uma das escolas, a biblioteca não funciona à tarde. As atividades de leitura e empréstimo de livros nesse turno são realizadas nas salas de aula pelas professoras, utilizando caixas de livros na própria sala, sem interação dos alunos com a biblioteca.

Sobre o acervo, destacam-se seis bibliotecas que atendem ao nível exemplar (quatro títulos por aluno). Entretanto, das 11 bibliotecas, apenas duas trabalham com um software de gerenciamento do acervo, as demais não realizam nenhum tipo de registro e/ou formato de classificação e catalogação.

Em relação aos serviços, foram elencadas nove modalidades que podiam ser ofertadas; destas alternativas o empréstimo de livros é realizado por todas as instituições, sendo o serviço mais utilizado pelos alunos. A consulta local só não foi mencionada por uma escola, já as feiras (eventos, oficinas, exposições) são realizadas em apenas duas bibliotecas.

A contação de histórias acontece em seis escolas; as atividades de 
incentivo à leitura são realizadas esporadicamente e, nem sempre, no espaço da biblioteca e com parceria entre professor e bibliotecário. Já as práticas de orientação à pesquisa foram mencionas em nove bibliotecas, mas os profissionais informaram que o espaço é pouco utilizado para este fim. Nas bibliotecas que não realizam orientação à pesquisa, em uma delas não há procura pelo serviço por parte da comunidade escolar; na outra, trabalhos escolares com utilização de pesquisa não são solicitados pelos professores.

$\mathrm{Na}$ questão solicitando que o bibliotecário elencasse até cinco atividades que gostaria que a biblioteca oferecesse, de um rol de 17 sugestões, a mais assinalada foi o aumento do acervo de livros (com oito respondentes), seguida de sorteio de livros (seis participantes), e empatadas três atividades com cinco votos: clube do livro, atividades dinâmicas de incentivo à leitura e concurso de desenho. Salienta-se que a única atividade que não foi escolhida por nenhum dos participantes foi a oficina de pesquisa.

Evidenciou-se que o uso da biblioteca e dos recursos disponibilizados é inabitual. Ou seja, os professores pouco a utilizam para e durante suas aulas. A maioria realiza as atividades de leitura em sala de aula; o que dificulta a integração da biblioteca e de seus profissionais com o professor e estudantes. $O$ mesmo ocorre em relação às práticas de pesquisa escolar e letramento informacional. Contudo, grande parte dos participantes percebeu a necessidade de adquirir conhecimentos para melhor utilizar a biblioteca escolar e desenvolver atividades que favoreçam a integração desse espaço com os educandos.

Ao analisar os dados coletados, para tecer reflexões entre o ideal e a realidade observada na biblioteca escolar, percebe-se um descompasso bem acentuado. Verificou-se que as escolas públicas municipais de Vacaria possuem bibliotecas que apresentam as seguintes características estruturais: coleções de livros de uso restrito; acervo 'trancado à chave' em armários, dificultando a circulação e uso por parte dos usuários; percepção de que a biblioteca é um espaço de armazenagem e guarda das obras. E ainda: o silêncio deve imperar, não oferecendo, assim, interação e/ou integração de quem a frequenta com o que ela disponibiliza.

Também se constatou no acervo um número expressivo de livros 
didáticos e/ou materiais de referência (dicionários, coleções antigas e enciclopédias desatualizadas). Há poucos materiais para pesquisa e informação (revistas e periódicos).

Atualmente, a demanda dos usuários se volta para produtos e serviços cada vez mais interativos, em especial, com suporte tecnológico. Portanto, os profissionais necessitam conhecer o papel da biblioteca e oferecer serviços que atendam as necessidades informacionais dos seus usuários, bem como daqueles que poderiam estar frequentando o espaço, mas por algum motivo não o fazem.

Embora os resultados tenham apresentado uma realidade diferente do que é proposto pelos parâmetros e critérios para as bibliotecas escolares, foi perceptível o interesse por parte dos participantes em adquirir habilidades e conhecimentos para melhor conduzir o trabalho pedagógico com a biblioteca. Mais de $90 \%$ dos participantes informaram ter interesse em participar de capacitação tendo como temática a biblioteca escolar, como mostra o gráfico a seguir.

Gráfico 1 - Participantes interessados em capacitação

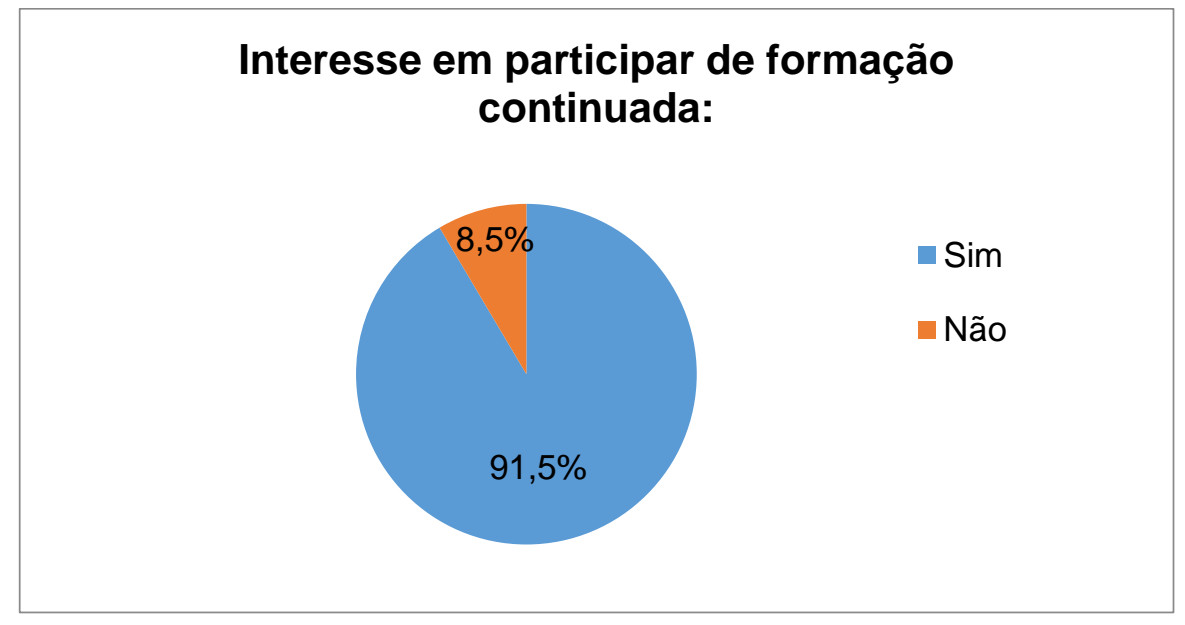

Fonte: Elaborado pela autora (2020)

Ao serem indagados sobre uma possível oferta de curso de formação continuada em Letramento Informacional e biblioteca escolar, $91,5 \%$ dos participantes mencionaram ter interesse em realizar a capacitação (43 de um total de 47 respondentes). 
Diante dessa receptividade em aprender, há exemplos de atividades e projetos que podem trazer transformações positivas no âmbito das bibliotecas escolares. São ideias que chamam a atenção pela simplicidade de recursos e facilidade de execução, podendo ser implantados nas unidades de informação pesquisadas visando à conquista de outros espaços, de novos usuários e 0 reconhecimento da biblioteca enquanto instância educativa e cultural dentro da comunidade escolar.

\section{FALANDO DO QUE EXISTE ENTRE O REAL E O IDEAL: O POSSÍVEL - INICIATIVAS E PROJETOS PARA BIBLIOTECAS ESCOLARES}

O diagnóstico das bibliotecas escolares da rede municipal de ensino de Vacaria, ao ser comparado com o ideal proposto pelos documentos normativos estudados, retrata uma situação preocupante que atinge todos os envolvidos com a educação básica escolar. Entretanto, é preciso que se crie a meta de chegar a esse ideal de biblioteca, mas trabalhando pelo viés das possibilidades, ou seja, aquilo que é possível realizar no momento.

Com base em vivências profissionais da pesquisadora como bibliotecária escolar e pedagoga, considerou-se importante apontar alguns projetos e atividades que foram organizados e colocados em prática pela proponente deste estudo. Essas sugestões podem ser difundidas e adaptadas a cada realidade existente, bem como serem incorporadas às atividades dessas bibliotecas escolares investigadas.

a) Eventos culturais: sarau literário-musical, concursos literários (redação, poesia, frase, desenho), palestras e seminários educativos, teatro, gincanas;

b) Mediação de leitura: hora do conto, encontro com o escritor, café literário, roda de leitura (clube). Além dessas ideias, têm-se:

- Pipocas literárias - projeto criado pela pesquisadora, que consistia em encontros mensais com alunos. Nestes encontros eram trabalhados com livros que foram adaptados para o cinema. $\mathrm{O}$ projeto consistia na leitura prévia da obra selecionada no mês e 
posterior sessão de cinema, finalizando com debate.

- Mural interativo - era um espaço da biblioteca de participação colaborativa. Todos os frequentadores da biblioteca deixavam suas impressões, sugestões, recados no mural. Os leitores deixavam bilhetes apreciativos das obras lidas dentro dos livros para que outros leitores pudessem conhecer um pouco do livro antes de levá-lo. Esse projeto foi desenvolvido pela pesquisadora.

- Projeto Livro de Anotar Livro - atividade feita pela pesquisadora com as turmas dos anos iniciais do ensino fundamental. Essa atividade fez parte do projeto de Letramento Informacional desenvolvido na biblioteca. Foram confeccionados, com os alunos, livros nos quais eram realizadas inúmeras atividades sobre as obras lidas: desenhos, ficha de leitura, resumos, anotações sobre livros que os colegas leram.

- Projeto Passeio das Letras - contou com a colaboração da Biblioteca Pública, elaborado com base no conceito de biblioteca itinerante. Buscou-se criar condições para o desenvolvimento da leitura nas famílias. Foram organizadas pastas com material diversificado para alcançar todos os membros da família.

c) Oficinas de arte: origami, bonecos e máscaras, datas comemorativas, confecção de marcadores de página e

- Sementes literárias - com livros de descarte é feito papel reciclável e incorporado a ele sementes de flores e hortaliças. O papel é recortado em formato de folha de árvore, os alunos escrevem pequenas frases de obras famosas ou versos de poesias selecionadas coletivamente. As sementes literárias podem fazer parte da feira do livro, sendo penduradas nas árvores próximas de onde ocorre o evento.

d) Cursos e projetos: oficinas de pesquisa, produção textual, formatação de trabalhos escolares, projeto de letramento informacional.

e) Eventos Pedagógicos: mostra pedagógica da escola, portfólios literários, feira do livro, troca-troca de livros usados; 
f) Durante a pesquisa exploratória três participantes mencionaram as seguintes atividades: 'Baú encantado', 'Pastas literárias' e 'Canto das histórias lidas'.

Todas essas iniciativas elencadas sustentam a importância da presença da biblioteca no espaço escolar, caracterizando-a como "[...] parte integrante do processo educativo" (IFLA, 2016, p. 70). Também reforçam o quanto a biblioteca pode ser um excelente caminho para desenvolver várias atividades e promover a aprendizagem dos alunos. Aqui foram citadas apenas algumas das tantas iniciativas que podem ser realizadas em conjunto com professores, equipe diretiva e bibliotecários, para que a biblioteca escolar se efetive como um espaço de aprendizagem e conhecimento, além de promotora de leitura.

\section{CONSIDERAÇÕES FINAIS}

Este estudo procurou tecer reflexões sobre a biblioteca escolar enquanto espaço educativo para o trabalho em parceria entre os agentes educacionais. Atualmente as bibliotecas escolares podem contar com normativas e documentos que norteiam seus princípios e suas práticas; esses parâmetros dão subsídios para a organização de uma biblioteca ideal. Entretanto, essa caminhada é realizada individualmente, ou seja, cada escola tem seu ritmo, seus anseios, suas dificuldades e oportunidades para alcançar esses parâmetros, umas antes, outras demorando um pouco mais.

Foi possível conhecer um panorama quanto ao número de escolas com presença de bibliotecas, profissionais que nelas atuam, acesso aos recursos tecnológicos, estrutura, serviços, utilização da biblioteca e percepções da comunidade escolar sobre ela. Entre os aspectos positivos encontrados, constatou-se que todas as intuições possuem espaços destinados a bibliotecas, bem como, mais da metade conta com um acervo considerado exemplar quanto ao número de títulos por aluno. Esse cenário indica que há um campo profícuo para compreender como as bibliotecas escolares da rede municipal de ensino de Vacaria são necessárias enquanto espaços educativos para contribuir com práticas e atividades pedagógicas, sendo promotoras de aprendizagem. 
Portanto, considera-se que analisar as ações das escolas do município de Vacaria - refletindo sobre a interação entre a biblioteca escolar e a sala de aula para o fazer pedagógico - é relevante à geração de novas discussões e possibilidades de ações conjuntas, por meio do trabalho colaborativo de todos os agentes da educação escolar.

Por fim, as 'amostras' de projetos e atividades apresentadas dão um vislumbre do potencial existente nas bibliotecas escolares. Acredita-se que a barreira entre $o$ ideal e 0 real nessas unidades de informação será mais facilmente quebrada com o que existe de intermediário entre esses dois conceitos: o possível. Provavelmente, seja inviável, no momento, principalmente pela realidade apontada na pesquisa, se pensar em propostas para implantar um ideal de biblioteca escolar, mas exemplos como os supracitados permitem a realização de significativas mudanças na realidade existente.

\section{REFERÊNCIAS}

BEDIN, J.; CHAGAS, M. T.; SENA, P. M. B. Competência informacional em biblioteca escolar: ações para o desenvolvimento. Revista ACB, Florianópolis, v. 20, n. 3, p. 363-372, set./dez., 2015. Disponível em:

https://revista.acbsc.org.br/racb/article/view/1105/pdf. Acesso em: 01 abr. 2020.

BRASIL. Lei n. 12.244, de 24 de maio de 2010. Dispõe sobre a universalização das bibliotecas nas instituições de ensino no País. Diário Oficial da União, Brasília, DF, 25 maio 2010. Disponível em: http://www.planalto.gov.br/ccivil_03/_ato2007-2010/2010/lei//12244.htm. Acesso em: 28 mar. 2020.

BRASIL. Projeto de Lei n. 9.484, de 06 de fevereiro de 2018. Altera a lei n.12.244, de 24 de maio de 2010. Brasília: Câmara dos Deputados Federal, 2018. Disponível em:

https://www.camara.leg.br/proposicoesWeb/fichadetramitacao?idProposicao=2 167716. Acesso em: 28 mar. 2020.

CAMPELLO, B. S. O movimento da competência informacional: uma perspectiva para o letramento informacional. Ciência da Informação, Brasília, v. 32, n. 3, set./dez., p. 28-37, 2003. Disponível em:

http://www.scielo.br/pdf/ci/v32n3/19021.pdf. Acesso em: 28 abr. 2020.

CONSELHO FEDERAL DE BIBLIOTECONOMIA. Resolução n. 220, de 13 de maio de 2020. Dispõe sobre os parâmetros a serem adotados para a 
estruturação e o funcionamento das bibliotecas escolares. Brasília: CFB, 2020. Disponível em:

http://repositorio.cfb.org.br/bitstream/123456789/1349/1/Resolu\%c3\%a7\%c3\%a 30\%20220\%20Par\%c3\%a2metros\%20biblioteca\%20escolar\%20\%281\%29.pdf. Acesso em: 14 mai. 2020.

CONSELHO FEDERAL DE BIBLIOTECONOMIA. Biblioteca escolar como espaço de produção do conhecimento: parâmetros para bibliotecas escolares. Belo Horizonte: [s.n.], 2010. Disponível em:

https://files.cercomp.ufg.br/weby/up/366/o/padroesparabibliotecasescolares.pdf. Acesso em: 23 abr. 2020.

CONSELHO REGONAL DE BIBLIOTECONOMIA. Biblioteca escolar modelo na Bienal Internacional do Livro. São Paulo: CRB8, 2018. Disponível em: http://www.crb8.org.br/biblioteca-escolar-modelo-na-bienal-internacional-dolivro-2018/. Acesso em: 23 abr. 2020.

DAS, L. H. Bibliotecas Escolares no século XXI: à procura de um caminho.

Rede de Bibliotecas escolares Newsletter, Lisboa, n. 3, out. 2008. Disponível em:

https://www.rbe.mec.pt/news/newsletter3/newsleter_n3_ficheiros/page0005.htm . Acesso em: 24. mar. 2020.

HILLESHEIM, A. I. de A.; FACHIN, G. R. B. Conhecer e ser uma biblioteca escolar no ensino-aprendizagem. Revista ACB: biblioteconomia em Santa Catarina, Florianópolis, v. 4, n. 4, p. 64-79, 1999. Disponível em: http://revista.acbsc.org.br/racb/article/view/340/403. Acesso em: 15 mar. 2020.

IFLA. Manifesto IFLA/UNESCO para biblioteca escolar: a biblioteca escolar no ensino e aprendizagem para todos. Tradução de Neusa Dias Macedo. São Paulo: IFLA, 2000. Disponível em: https://www.ifla.org/files/assets/schoollibraries-resource-centers/publications/school-library-manifesto-pt-brazil.pdf. Acesso em: 11 abr. 2020.

IFLA. Diretrizes da IFLA para a biblioteca escolar. Tradução de Rede de Bibliotecas Escolares. Portugal, 2016. Disponível em:

https://www.ifla.org/files/assets/school-libraries-resourcecenters/publications/ifla-school-library-guidelines-pt.pdf. Acesso em: 11 abr. 2020.

MAROTO, L. H. Biblioteca escolar, eis a questão: do espaço do castigo ao centro do fazer educativo. Belo Horizonte: Autêntica, 2009.

RIO GRANDE DO SUL. Secretaria da Educação. Porto Alegre:

SEDUC/SEBE, [2019?]. Disponível em: https://servicos.educacao.rs.gov.br/pse/html/sebe.jsp?ACAO=acao1. Acesso em: 03 mai. 2020. 
RIO GRANDE DO SUL. Secretaria da Educação. Manual de procedimentos voltado à dinamização das bibliotecas escolares estaduais do Rio Grande do Sul. Porto Alegre: SEDUC/SEBE, 2014. Disponível em:

https://servicos.educacao.rs.gov.br/dados/sebe_manual_biblioteca.pdf. Acesso em: 03 mai. 2020.

\title{
DIAGNOSIS OF MUNICIPAL SCHOOL LIBRARIES IN VACARIA (RS): CURRENT SITUATION AND PERSPECTIVES
}

\begin{abstract}
Introduction: This is article presents partial results of the ongoing research of a Professional Master's in Information Units Management at the State University of Santa Catarina. It explores the subject of the school library as an educational space and as a pedagogical support to the partnership work between teachers and librarians; bringing the context of the municipal public schools of Vacaria in the state of Rio Grande do Sul (Brazil). Objective: Diagnosing how these school libraries are configured in relation to their spaces and services, as well as to the educational practices for elementary school students. Methodology: It is an exploratory field research, with a qualitative approach, in which the investigative corpus consists of 11 public schools located in the city Vacaria (RS). These schools are analyzed based on Resolution n. 220/2020 of the Federal Council of Library Science, on the Parameters for Brazilian School Libraries (CFB; GEBE, 2010), on the IFLA Guidelines for the school library (IFLA, 2016), and theoretical references. Results: It was found that all the 11 schools have space for library, 6 of them have a collection considered exemplary (with four titles per student). The participants showed interest in acquiring knowledge through training in order to better utilize the school library. However, it was found that the investigated libraries need to implement adequately the normative parameters analyzed. Conclusions: It was possible to know the educational environment of the city of Vacaria (RS) in regard to the school library number of schools with libraries, professionals, technological resources, structure, services, use of the library, and the scholar community perception about it.
\end{abstract}

Descriptors: School Library. Parameters for School Library. Diagnosis of Libraries. Educational Practices.

\section{DIAGNÓSTICO DE LAS BIBLIOTECAS DE LAS ESCUELAS MUNICIPALES EN VACARIA: SITUACIÓN ACTUAL Y PERSPECTIVAS}

\section{RESUMEN}

Introducción: Este artículo presenta los resultados parciales de la investigación en curso de Maestría Profesional en Gestión de Unidades de Información, de la Universidad del Estado de Santa Catarina. Explora el tema de la biblioteca escolar como un espacio educativo y de apoyo al trabajo de los maestros con los bibliotecarios; trayendo el contexto de las escuelas municipales de Vacaria, en el interior del Río 
Grande del Sur. Objetivo: Diagnosticar cómo se configuran estas bibliotecas escolares en relación a sus espacios y servicios, así como las prácticas educativas dirigidas a los estudiantes en los primeros años de la escuela primária. Metodología: Es una investigación de campo, exploratoria, con un enfoque cualitativo, cuyo corpus investigativo consta de 11 escuelas públicas ubicadas en la ciudad de Vacaria (RS). Estas escuelas se analizan de acuerdo con la Resolución n.ำ 220/2020 del Consejo Federal de Biblioteconomía, de los Parámetros para las Bibliotecas Escolares Brasileñas (CFB; GEBE, 2010) y las Directrices de la IFLA para la biblioteca escolar (IFLA, 2016), e referencias teóricas. Resultados: Se encontró que las 11 escuelas tienen espacio para la biblioteca, seis de ellas tienen una colección considerada ejemplar (con cuatro títulos por alumno). Los participantes están interesados en adquirir conocimiento mediante capacitación para usar mejor la biblioteca en la escuela. Sin embargo, se descubrió que las bibliotecas investigadas deben adaptarse a los parámetros normativos estudiados. Conclusiones: Fue posible conocer el escenario educativo de la ciudad de Vacaria con respecto a la biblioteca escolar: número de escuelas con presencia de bibliotecas, profesionales, recursos tecnológicos, estructura, servicios, uso de la biblioteca y percepciones de la comunidad escolar sobre ella.

Descriptores: Bibliotecas Escolares. Parámetros para Biblioteca Escolar. Diagnóstico de Bibliotecas. Prácticas Educativas.

Recebido em: 17.10 .2020

Aceito em: 18.11 .2020 